\title{
plasticidad de las materias primas $y$ de las pastas cerámicas
}

(La plasticité des matières premières et des pâtes céramıques)

A. BAUDRAN

De: «Silicates Industriels», vol. XXI, núm. 5, mayo 1956, pág. 219

En un cuerpo plástico ideal, un esfuerzo cortante no produce ninguna deformación hasta que no se ha alcanzado el límite de elasticidad. Por encima de este límite, la velocidad de deformación es proporctonal al esfuerzo.

El autor ha observado que el comportamiento de las pastas cerámicas difiere sensiblemente del de un cuerpo plástico ideal; por este motivo há estudiado la relación entre el esfuerzo, el tiempo y la deformación en los diversos procesos de moldeo. Para tal objeto emplea un plasticímetro, utilizado por el Service des Recherches Technfques de la Société Française de Céramique para determinar la influencia del modo de preparación de las pastas sobre su plasticídad. Este aparato se proyectó con el fin de poder someter, a diferentes velocidades, constantes a lo largo de cada ensayo, una probeta en forma de tubo a un esfuerzo cortante, así como para registrar la curva esfuerzo-deformación. Esta curva da el esfuerzo y la deformación en el límite elástico, el esfuerzo máximo y la deformactón correspondlente, asi como el esfuerzo y la deformación en el momento de la rotura.

Las características de una pasta, que se ha de moldear por extrusión, quedan de manifiesto por la forma de la curva que se obtiene con una arcilla destinada a la fabricación de ladrillos; el límite de elasticidad se encuentra por encima del punto en que la pasta se deforma de modo uniforme bajo un esfuerzo importante. Esta es la condición necesaria para que los ladrillos conserven su forma, una vez que han salido de la boquilia.

Se ha examinado la influencia de la velocidad de deformación. Se ha observado que para velocidades crecientes, crecen el esfuerzo máximo y la deformación correspondiente, así como el esfuerzo y la deformación en el momento de la rotura. Se puede aflrmar que, en clertos casos, es posible evitar la rotura de la pasta durante el moldeo sin más que aumentar la velocidad de deformación.

El fenómeno de la memoria de la pasta indica que ésta conserva todas o parte de sus propiedades elásticas cuando desaparece el esfuerzo, que ha provocado una deformación elástica seguida de una deformaclón plástica, pero sin Ilegar a la rotura. La comprobación se ha llevado a cabo en una probeta tubular, sujeta por uno de sus extremos, mlentras que por el otro se encuentra sometida a un giro tal, que se sobrepase el limite elástico, aunque sin que se produzca la rotura. En el momento en que se suprime el esfuerzo se observa una recuperación, casi Instantánea al principio, pero mucho raás tenta después. 
Según la curva de deformación, el esfuerzo aumenta a partir del límite elástico, de forma que se puede deducir que, bajo un esfuerzo constante, la velocidad de deformación debe disminulr. Mediante un modelo mecánico el autor explica por qué, en la curva obtenida mediante el plasticímetro, el esfuerzo dismínuye después de haber pasado por un máximo, aunque la deformación haya tenido lugar a velocidad constante. Se propone comprobar su hipótesis mediante un dispositivo que permita aplicar y suprimir el esfuerzo y controlar simultáneamente las variaciones en el contenido en agua.

S. F. S. 